\title{
Botulismo tipo C em perus em Minas Gerais, Brasil
}

\author{
Type C botulism in turkeys in Minas Gerais, Brazil
}

\begin{abstract}
Francisco Carlos Faria Lobato ${ }^{\mathrm{I}^{*}}$ Felipe Masiero Salvarani ${ }^{\mathrm{I}}$ Rodrigo Otávio Silveira Silva ${ }^{\mathrm{I}}$ Ronnie Antunes de Assis ${ }^{\text {II }}$ Luis Alberto do Lago ${ }^{\text {III }}$ Maurício Baltazar de Carvalho Filho ${ }^{\text {II }}$ Nelson Rodrigo da Silva Martins ${ }^{\mathrm{III}}$
\end{abstract}

\begin{abstract}
O botulismo é uma intoxicação causada pela RESUMO ingestão das toxinas produzidas pelo Clostridium botulinum, que acomete mamíferos e aves e é caracterizado por um quadro de paralisia flácida. Neste trabalho, é descrito um surto de botulismo em perus, ocorrido no município de Santa Luzia, região metropolitana de Belo Horizonte, Minas Gerais. Os animais apresentavam incoordenação motora, paralisia flácida das patas, asas e pescoço. Em um intervalo de 24 horas, todos os 29 animais do plantel vieram a óbito. Na necropsia, observou-se a presença de larvas de mosca no inglúvio. Nos soros coletados, foi identificada a toxina botulínica tipo $C$ pelo teste de soroneutralização em camundongos.
\end{abstract}
Palavras-chave: toxina botulínica tipo C, Clostridium botulinum, perus, aves.

\section{ABSTRACT}

Botulism is an intoxication caused by the ingestion of toxins produced by Clostridium botulinum. It affects mammals and birds, and is characterized by flaccid paralysis of the limbs. This report describes an outbreak of botulism in turkeys of various ages in the city of Santa Luzia, state of Minas Gerais, Brazil. The animals showed incoordination followed by flaccid paralysis involving the muscles of the legs, wings and neck. Within 24 hours, all 29 (100\%) turkeys died. The post-mortem examination revealed the presence of fly larvae in the crop and the $\boldsymbol{C}$. botulinum type $\boldsymbol{C}$ toxin was demonstrated in the sera of two affected animals by serum neutralization test.
Key words: botulism type C, Clostridium botulinum, turkey, birds.

O botulismo, que acomete aves e mamíferos, é causado pela ingestão de uma neurotoxina letal produzida pelo Clostridium botulinum, que é a mais potente toxina de origem microbiológica conhecida. Resistente à ação proteolítica, ela é absorvida pela mucosa intestinal e age nas placas neuromusculares impedindo a liberação do neurotransmissor acetilcolina, resultando em um quadro de paralisia flácida (ALMEIDA et al., 2000; TAKEDA et al., 2005).

C. botulinum é uma bactéria Gram-positiva, anaeróbia obrigatória e ubiquitária, com esporos altamente resistentes e difundidos no ambiente. $\mathrm{O}$ agente se desenvolve em vários tipos de substratos, tais como cadáveres, alimentos e tecidos vegetais em putrefação, poças e lagoas com água estagnada, desde que haja um ambiente favorável associado às condições de anaerobiose que permitam sua multiplicação. As larvas de muscídeos, que comumente se desenvolvem em matéria orgânica em decomposição, são resistentes à toxina botulínica e concentram-na em seu organismo, sendo uma fonte de intoxicação comum para aves (TAKEDA et al., 2006).

\footnotetext{
'Laboratório de Bacteriose e Pesquisa, Escola de Veterinária, Universidade Federal de Minas Gerais (UFMG). Belo Horizonte, MG, Brasil. E-mail: flobato@vet.ufmg.br.*Autor para correspondência.

IIMinistério da Agricultura, Pecuária e Abastecimento, Portal Nacional Agropecuário (LANAGRO-MG), Setor de Clostridioses, Pedro Leopoldo, MG, Brasil.

IIIEscola de Veterinária, UFMG, Belo Horizonte, MG, Brasil.
} 
Existem sete tipos de $\boldsymbol{C}$. botulinum, classificados de $A$ até $\mathrm{G}$, sendo o tipo $\mathrm{C}$ o principal responsável por casos de botulismo em aves (WOBESER, 1997). O período de incubação da doença varia desde algumas horas até dois dias após a ingestão da toxina, enquanto a gravidade e a duração dos sinais clínicos variam pela quantidade de toxina ingerida. Clinicamente, o botulismo em aves é caracterizado pela paralisia flácida simétrica ascendente, acometendo inicialmente as patas e prosseguindo para as asas, o pescoço e as pálpebras (TRAMPEL et al., 2005). O psiquismo, porém, permanece inalterado e comumente nenhuma alteração significativa é visualizada no exame post-mortem (LINARES et al., 1994). Em perus, os músculos das patas e das asas parecem ser os mais severamente afetados pela toxina botulínica (JEFFREY et al., 1994).

O diagnóstico baseia-se nos sinais clínicos e na detecção da toxina botulínica. Esta se encontra em elevada concentração no sangue das aves, sendo possível usar o soro destes animais para determinar especificamente qual a toxina envolvida por meio da técnica de soroneutralização em camundongo (SMITH, 1983).

No Brasil, são escassos os relatos da ocorrência de botulismo em aves. Portanto, este trabalho teve por objetivo descrever um surto de botulismo em perus (Meleagris gallopavo) de subsistência, ocorrido no município de Santa Luzia, em Minas Gerais, Brasil.

O plantel era composto de 29 animais, sendo cinco reprodutores machos, 15 fêmeas adultas e nove aves jovens com aproximadamente quatro meses de idade. Os animais eram criados em um regime extensivo, porém, eram recolhidos em um galpão durante a noite, onde recebiam ração comercial balanceada e frutas.

Durante a abertura do galpão na manhã do dia 15 de maio de 2006, foram observadas quatro fêmeas adultas e duas jovens em decúbito esternal e, quando forçadas a se movimentar, apresentavam marcha cambaleante e incoordenação motora. O quadro evoluiu para paralisia das patas, das asas e do pescoço, entretanto, o psiquismo permanecia inalterado. Decorridas 14 horas do início dos sinais clínicos, esses animais vieram a óbito. À noite, apenas 11 animais foram novamente recolhidos para o galpão, sendo que na manhã do dia seguinte eles apresentaram os mesmos sinais clínicos descritos. Os outros 12 animais que não retornaram ao galpão foram encontrados mortos próximos a uma área de compostagem orgânica, onde foi possível identificar grandes bolsas de larvas de moscas. Dois animais ainda vivos foram encaminhados para o Laboratório de Doenças das Aves da Escola de
Veterinária da Universidade Federal de Minas Gerais (UFMG), onde foi realizada a coleta de sangue e a necropsia. O soro obtido foi encaminhado para o Setor de Clostridioses do Laboratório Nacional Agropecuário de Minas Gerais (LANAGRO-MG) para pesquisa da toxina botulínica por meio da técnica de soroneutralização em camundongos, conforme metodologia descrita por SEBALD \& PETIT (1997). Não houve envolvimento de nenhuma outra espécie animal.

No presente surto, foi observada uma variação da duração dos sinais clínicos, como já relatado em surtos anteriores (LINARES et al., 1994; TRAMPEL et al., 2005). De acordo com JEFFREY et al. (1994), os sinais clínicos do botulismo em aves são dose dependente, o que pode explicar a ocorrência de diferentes durações e a variação da severidade dos sintomas. A necropsia não revelou lesões significativas, sendo possível identificar apenas larvas de moscas no inglúvio. Os sinais clínicos observados e a ausência de alterações post-mortem significativas são observadas nos quadros de botulismo e foram anteriormente descritas, assim como a presença de larvas de mosca no inglúvio das aves acometidas (WOBESER, 1997; PIGATTO et al., 2007; LOBATO et al., 2008).

No bioensaio, todos os camundongos que receberam o soro suspeito puro apresentaram dispnéia e "cintura de vespa”, que ocorre devido ao aumento da flacidez dos músculos costais e abdominais (LINDSTRÖM \& KORKEALA, 2006). Os animais que receberam a mistura do soro com a antitoxina botulínica tipo D morreram. Já os que receberam a mistura do soro com a antitoxina botulínica tipo $\mathrm{C}$ e o soro aquecido a $100^{\circ} \mathrm{C}$ sobreviveram.

Com base nos sinais clínicos e na tipificação pela soroneutralização, foi possível firmar o diagnóstico de botulismo causado pela toxina botulínica tipo C. Acredita-se que a fonte de toxina tenha sido larva de muscídeos, encontrada no inglúvio das aves, oriunda do material em compostagem. Segundo a literatura consultada, este parece ser o primeiro surto de botulismo em perus descrito no Brasil.

Vários estudos têm sido conduzidos com intuito de avaliar o efeito da imunização contra toxina botulínica em aves. Em alguns países, a vacinação de aves tem demonstrado eficácia como medida preventiva, diminuindo a mortalidade em surtos (MARTINEZ \& WOBESER, 1999; ROCKE et al., 2000; ARIMITSU et al., 2004). Porém, não há vacina comercial disponível para utilização no Brasil. Com isso, o presente relato demonstra a necessidade de prevenir o acesso de animais a potenciais fontes de intoxicação, em especial a áreas de compostagem e carcaças em 
decomposição. Para aves aquáticas, lagoas ou outras fontes de água estagnada também podem representar risco, principalmente quando contaminadas com carcaças ou na época de seca, quando o volume destas diminui, expondo matéria orgânica vegetal em putrefação em sua margem (GALVIN et al., 1985).

Não há tratamento eficiente para botulismo, sendo que este se baseia na terapia de suporte. As antitoxinas, além de pouco disponíveis no mercado brasileiro, agem apenas na toxina circulante, não tendo efeito algum na toxina já ligada. Além disso, na maioria casos, o tratamento é pouco viável para aves devido ao grande número de animais acometidos e pela recuperação difícil e demorada (PECELUNAS et al., 1999; KURTDEDE \& SANCAK, 2002).

É interessante salientar ainda que, comparadas aos mamíferos, as aves são mais resistentes à toxina botulínica. Porém, os perus são particularmente mais sensíveis, cerca de 50 vezes mais do que galinhas. Assim, como a toxina botulínica liga-se irreversivelmente à junção neuromuscular, parte dela é retirada da circulação e não estará disponível para detecção no soro para diagnóstico. Desse modo, devese preferencialmente coletar soro de animais com sinais clínicos agudos ou que morreram a pouco tempo, evitando aqueles que apresentaram sinais clínicos brandos ou de duração longa ou desconhecida (JEFFREY et al., 1994).

\section{REFERÊNCIAS}

ALMEIDA, A.C. et al. Perfil sorológico das amostras de Clostridium botulinum tipos C e D utilizadas para produção de imunógenos no Brasil. Arquivo Brasileiro de Medicina Veterinária e Zootecnia, v.52, n.2, p.91-95, 2000.

ARIMITSU, H. et al. Vaccination with recombinant whole heavy chain fragments of Clostridium botulinum Type $\mathrm{C}$ and $D$ neurotoxins. Clinical and diagnostic Laboratory Immunology, v.11, n.3, p.496-502, 2004.

GALVIN, J.W. et al. An outbreak of botulism in wild waterbirds in southern Australia. Journal of Wildlife Diseases, v.21, n.4, p.347-350, 1985.

JEFFREY, J.S. et al. Type C botulism in turkeys: determination of the median toxic dose. Journal of Veterinary Diagnostic Investigation, v.6, p.93-95, 1994.
KURTDEDE, A.; SANCAK, A.A. Botulism in a long-legged buzzard (Buteo rufinus). Veterinary Record, v.151, n.2, p.64, 2002.

LINARES, J.A. et al. An outbreak of botulism in pheasants and subsequent occurrence in chickens. Journal of Veterinary Diagnostic Investigation, v.6, p.272-273, 1994.

LINDSTRÖM, M.; KORKEALA, H. Laboratory diagnostics of botulism. Clinical Microbiology Reviews, v.19, n.2, p.298-314, 2006.

LOBATO, F.C.F. et al. Caso de botulismo tipo C em ganso ocorrido em Minas Gerais, Brasil. Ciência Rural, v.38, n.4, p.1179-1180, 2008.

MARTINEZ, R.; WOBESER, G. Immunization of duck for type C botulism. Journal of Wildlife Disease Association, v.35, n.4, p.710-715, 1999.

PECELUNAS, K.S. et al. Botulism in Chickens Associated with Elevated Iron Levels. Avian Diseases, v.43, p.783-787, 1999.

PIGATTO, C.P. et al. Intoxicação natural por Clostridium botulinum tipo $\mathrm{C}$ em grupo de aves domésticas. Archives of Veterinary Science, v.12, n.2, p.12-16, 2007.

ROCKE, T.E. et al. Efficacy of a type C botulism vaccine in green-winged teal. Journal of Wildlife Disease, v.36, n.3, p.489-493, 2000.

SEBALD, M.; PETIT, J. C. Méthodes de laboratoire bactéries anaérobies et leur identification. Paris: Institut Pasteur. Deuxième édition augmentée, 1997. 307p.

SMITH, G.R. Diagnosis of botulism in water birds. Veterinary Record, v.112, p.457-458, 1983.

TAKEDA, M. et al. Characterization of the neurotoxin produced by isolates associated with avian botulism. Avian Diseases, v.49, p.376-381, 2005.

TAKEDA, M. et al. Protective effect of botulism C/D mosaic toxoid against avian botulism. Journal of Veterinary Medicine Science, v.68, p.325-330, 2006.

TRAMPEL, D.W. et al. Toxicoinfectious botulism in commercial caponized chickens. Avian Disease, v.49, p.301303, 2005.

WOBESER, G. Avian botulism - Another perspective. Journal of Wildlife Diseases, v.33, p.151-156, 1997. 